Georgia State University

ScholarWorks @ Georgia State University

\title{
Are There Distinct Employment Systems? New Evidence from American Firms
}

Bruce E. Kaufman

Georgia State University, bkaufman@gsu.edu

Benjamin I. Miller

Deloitte Tax LLP, bemiller@deloitte.com

Follow this and additional works at: https://scholarworks.gsu.edu/uwrg_workingpapers

\section{Recommended Citation}

Kaufman, Bruce E. and Miller, Benjamin I., "Are There Distinct Employment Systems? New Evidence from American Firms" (2009). UWRG Working Papers. 134.

https://scholarworks.gsu.edu/uwrg_workingpapers/134

This Article is brought to you for free and open access by the Usery Workplace Research Group at ScholarWorks @ Georgia State University. It has been accepted for inclusion in UWRG Working Papers by an authorized administrator of ScholarWorks @ Georgia State University. For more information, please contact scholarworks@gsu.edu. 
Working Paper 2009-2-2

February 2009

\section{Are There Distinct Employment Systems? New Evidence from American Firms}

Bruce E. Kaufman Georgia State University

Benjamin I. Miller Deloitte Tax LLP 


\title{
Are There Distinct Employment Systems? New Evidence from American Firms
}

\author{
Bruce E. Kaufman \\ Department of Economics and W.T. Beebe Institute of Personnel \& Employment Relations \\ Georgia State University \\ Atlanta, GA 30303 \\ bkaufman@gsu.edu \\ and \\ Benjamin I. Miller \\ Southeast Transfer Pricing Group \\ Deloitte Tax LLP \\ Atlanta, GA 30303 \\ bemiller@deloitte.com
}

February 19, 2009 
Are There Distinct Employment Systems? New Evidence from American Firms

Abstract: Theorizing in strategic human resource management has identified a "configurational" perspective in which firms put together distinct bundles of HRM practices called "employment systems" in order to exploit complementarities and synergies. This paper provides the most sophisticated and in-depth empirical test of this hypothesis to date. After surveying various typologies of employment systems, we select the one providing the most detailed predictions on alternative configurations of specific HRM practices. Using recent data on HRM practices among several hundred American firms, we find strong support for this particular model, the general idea of employment systems, and the configurational perspective.

Two decades ago research in human resource management (HRM) typically focused on individual HRM practices, often in a piece-by-piece type analysis. Since then, the blossoming of a strategic perspective has broadened attention from the individual practice level to HRM practices as a complete set or system within the firm. With the recognition that firms adopt different strategies for attaining competitive advantage and face different internal and external contingencies, the question soon arose among researchers: do these strategic and contingent factors cause firms to adopt different bundles of HRM practices and, if so, is there infinite variety in these bundles or do they sort into a smaller set of distinct employment systems?

Research on employment systems (ES's) has developed along two fronts. The first is at a theoretical level and involves an effort to identify the contours of alternative ES's and the factors that determine their shape and characteristics. A variety of models and typologies have been developed, as reviewed in more detail below. The second stream of research is empirical and endeavors to test these alternative models and, more generally, assemble evidence on whether HRM bundles among firms do in fact form distinct systems. 
This paper contributes to the empirical stream of research on employment systems. In particular, we focus on the typology of ES's developed by James Begin (1991) from the earlier work of Henry Mintzberg (1983). Mintzberg hypothesized that organizations develop into six alternative configurations; Begin used this typology of organizations to develop an equivalent typology of distinct employment systems. His theoretical development and articulation of these models is insightful. More important for our purpose, however, is the fact that Begin also describes in greater detail than other authors specific HRM practices that go with each of the ES models, thus providing greater opportunity for empirical testing of the employment systems idea.

The contribution of this paper, therefore, is to subject one particular theory of ES's to an empirical test. To do so, we first outline the four most distinctly different employment systems that emerge from Begin's typology and then identify the bundle of HRM practices associated with each. Next, we describe a large data set with a detailed list of HRM practices used by several hundred American firms. Using cluster analysis, we then see if the HRM practices across

firms sort into these four employment systems. We find a high level of conformance. These results, in addition to being innovative with respect to data and design, provide additional empirical support for the existence of distinct employment systems, as predicted by the configurational perspective in strategic human resource management.

\section{Employment Systems: A Brief Literature Review}

Attention to the concept of employment systems in HRM research is to a significant degree coterminous with the development of theoretical models of strategic human resource management (SHRM), beginning mostly in the 1990s and then accelerating to the present. The concept has its roots, however, in industrial relations and institutional labor economics. 
Commons (1919) described five different employment models, Kerr (1954) developed the internal labor market (ILM) idea and described two alternative ILM configurations, Dunlop (1958) advanced the notion of systems of industrial relations, and Osterman (1987) further refined the ILM concept into four alternative ES's. These ideas were introduced into HRM in the 1980s and 1990s by several writers (e.g., Mahoney and Deckop, 1986; Pinfield and Berner, 1994; Marsden, 1999) but gained limited traction. This situation is even more true for another group of models developed in the neo-Marxist labor process literature - a line of theorizing that portrays ES's as alternative systems of labor control (Edwards, 1979; Thompson and Harley, 2007).

The situation in the mainstream management literature fundamentally changed with the development of the subfield of strategic HRM in the 1980s and 1990s (Fombrun, Tichy, and Devanna, 1984). SHRM takes a more expansive firm-level view of HRM and, in particular, how the HR function and HRM activities should be structured to promote maximum firm performance. The perception was that early HRM, and more particularly its predecessor personnel management, had erred by looking at individual HRM practices in isolation rather than as a synergistic package. An influential early statement along this line is by Wright and McMahan (1992) who noted: "each of the various HRM functions have evolved in relative isolation from one another, with little coordination across the disciplines" (p. 297). They then describe perhaps the two key propositions of SHRM. In their words (p. 298), "First, vertically, it entails the linking of human resource management practices with the strategic management process of the organization... Second, horizontally, it emphasizes the coordination or congruence among various human resource management practices..." 
Whether the "silo" approach to personnel/HRM is a valid characterization and critique has been disputed (Kaufman, 2001, 2008), but it nonetheless seems accurate to say that this is the common perception both then and now. Inevitably, if one is looking at individual HRM practices in isolation, then the concept of an ES is certain to be too "macro" to be of much relevance. The purpose of SHRM, however, was precisely to give HRM this more macro organization-level focus, and the emphasis by writers such as Wright and McMahan on what soon became known as "vertical fit" and "horizontal fit" quickly invigorated interest in the ES concept.

In particular, early SHRM writers took the idea of vertical fit and tried to first identify different typologies of business strategies (prospector vs. defender; cost minimization vs. product differentiation) and then adduce the type of HRM strategy/program that best aligns with these alternative business strategies (e.g., Arthur, 1994). Once an overall HRM strategy was identified, then attention turned to the issue of horizontal fit and how individual components of HRM practice should be best mixed and matched to achieve the optimally aligned and synergistic ES.

New contributions to SHRM theorizing gave further impetus to interest in ES's. A prime example is the paper by Delery and Doty (1996). They argued that SHRM primarily utilizes three models of HRM choice: universalistic, contingency and configurational. The universalistic perspective argues that there is in the main one ES that is always and everywhere the best HRM program for maximizing organizational performance. This type of ES is typically called a "high performance" work system and contains elements such as widespread information sharing, employee empowerment, self-managed teams, extensive training, gain-sharing, and an egalitarian culture. The contingent perspective argues, on the other hand, that there is no one best ES; rather, the choice of ES varies with contingent external and internal organizational and environmental factors (e.g., nature of the firm's production technology, employee skills and 
knowledge, macroeconomic boom or bust). Illustratively, Delery and Doty contrast two alternative contingent ES's: a "market-type" and "internal" system. The former uses (for example) primarily market-based pay, features "hire and fire" staffing methods and provides little formal employee voice, while the latter provides forms of organizational gain-sharing, employment security, and formal voice mechanisms. The third perspective, configurational, is particularly concerned with mixing and matching individual HRM practices to exploit sources of (non-linear) synergy and complementarity. It is the configurational perspective that suggests the number of ES's are finite and, indeed, perhaps relatively few in number to the degree that strong complementarities make only certain combinations of HRM practice competitively viable.

Another SHRM theory contribution that has significant relevance to ES's is by Lepak and Snell (1999). They argue that a central responsibility of HRM is to allocate and manage an organization's human capital. They identify two central attributes that distinguish human capital across firms: "value" and "uniqueness." Taking a contingency perspective and using insights from the resource-based view of the firm, transaction cost theory and other models, Lepak and Snell claim that considerations of value and uniqueness predict firms will sort into four distinct employment systems or "HR architectures.” They label these ES's, respectively, "developing human capital," "acquiring human capital," "contracting human capital," and "creating human capital alliances." They then use the configurational perspective to develop a typology of HRM practices that group together in each architecture. Firms that use a human capital development ES, for example, are predicted to provide: extensive firm-specific training, significant job security, formal employee involvement/participation methods, skill-based or performance-based pay, and broader and more flexible job duties. 
To round out the discussion, one other ES typology is briefly highlighted. Hendry (2003) argues that ES's form around two axes: form of control (Personal, Organizational, Market) and skill (Low, High). The combinations within this 3 x 2 matrix yield six ES's: Associate, Career, Occupational/Professional, Family/Political, Industrial/ Clerical, and Market. To this list of six ES's he then adds two new “emergent” ES's: Commitment and Performance Management. Each ES has a distinct set of HRM practices; the Occupational model, for example, features high mobility across firms and general forms of training (e.g., the ES for nurses) while the Industrial features the reverse (the ES in steel mills).

This discussion gives a flavor of the theoretical side of the ES literature; now we turn to the empirical side. Since a key construct in the theory of ES's is the notion of complementarity, one route empirical studies have taken is to test for evidence of complementarities among HRM practices. A representative study of this sort is Black and Lynch (2001). They tested for complementarities by using interaction terms among select HRM practices in an HRM-firm performance regression model. Partial evidence of complementarities is found; for example, a TQM (total quality management) program has no independent effect on firm performance but does have a positive effect when combined with an employee voice/participation program. A more recent example is a study by Horgan and Mülau (2005). They find for Irish firms (but not Dutch firms) that the effect of five "high performance" HRM practices (incentives, training, sharing, guidance, and selection) is larger when used as a group then when used additively (oneby-one), thus again indicating the existence of HRM complementarities.

Empirical studies of employment systems can be divided into "micro" (firm-level) and "macro" (national-level). We note the latter, such as a comparison of the HRM/employment 
systems in countries such as the USA, Japan, and Germany (Begin, 1997; Katz and Darbishire, 2000; Pudelko, 2006), but focus on the former since our study is also at the firm level.

A pioneering empirical study of employment systems is by Arthur (1992). Following Walton (1985), he distinguishes between two ES's: a "control" ES and "commitment" ES. HRM characteristics of the control ES include narrow job tasks, tight supervision, limited training, narrow incentive pay, and little formal voice; characteristics of the commitment ES include broadly defined jobs, self-managing teams, extensive training, and broad-based gain-sharing forms of pay. Arthur used cluster analysis on a sample of steel mini-mills and found that the plants did sort into two groups of HRM bundles broadly similar to the hypothesized control and commitment models and, further, that the choice of ES system was systematically related to the firm's business strategy (low cost vs. product differentiation).

Another early and influential ES study is by MacDuffie (1995). He assembled data on a wide range of firm-level characteristics related to the production and HRM systems in auto assembly plants. Using cluster and factor analysis, he found the plants sorted into three distinct types of production systems, called "mass production," "transition," and "flexible production." Each production system, in turn, had an associated employment system. The mass production ES, for example, utilized few teams, few voice mechanisms, and little enterprise gain-sharing, while the flexible production system used much larger amounts of all three.

We cite one other ES study from the 1990s that was particularly innovative and insightful. Baron, Burton, and Hannan (1999) examined one hundred start-up firms in Silicon Valley and obtained from the companies' founders a descriptive "blue print" of the HRM system they installed. They determined that the three most important dimensions of the individual ES's 
were, respectively, the philosophies/practices used for employee attachment, selection and work control, and that each of the three dimensions were in turn sub-divided along three dimensions (e.g., attaching people to work through "love," "money," and "work"). Out of a total of twentyseven possible configurations, the researchers found that the one hundred firms actually sorted into four distinct patterns of HRM usage: a "star," "engineering," “commitment," and "factory" ES. The factory ES, for example, used pay to attract/retain labor, formal rules and procedures to control the work process, and hired people having specific and ready-to-go job skills. The star ES, on the other hand, used interesting work to attract and retain, professional norms and training to control the work process, and hired people with high long-run performance potential.

These three studies provide representative examples of foundational empirical work on ES's. A number of more recent empirical studies of ES's build on this earlier literature. Examples include Appelbaum, et. al. (2000), Guthrie (2001), and Orlitsky and Frenkel (2005), with particular attention on the high performance type ES (Boxall and Macky, 2009). Most use some version of cluster or factor analysis. Out of this research have come a number of additional typologies of ES's, such as "traditional," "incentive," "participatory" and "high performance" (Appelbaum, et. al.,) and "enabler" and "coercive" (Orlitzky and Frenkel). These studies find further evidence on the existence of HRM complementarities and the empirical relevance of the SHRM configurational perspective.

Therefore, as a summary statement it seems fair to assert two propositions. The first is that the ES literature has advanced far enough to have given the concept of an employment system a ground-level foundation of theoretical and empirical support; the second is that this research program is still in an early stage with much further work needed to develop and 
synthesize alternative ES models and better empirically map the contours of these models. It is this last goal that we seek to advance.

\section{Begin's Typology of Employment Systems}

Begin's work on employment systems remains relatively unknown and rarely cited and yet is among the most in-depth and analytically advanced in the ES literature. Further, Begin builds his ES model on the highly respected work of organizational theorist Henry Mintzberg, especially Mintzberg's book Structure in Fives: Designing Effective Organizations (1983). One contributing factor to this paradox is that Begin never published a more accessible and compact version of his ES model in a mainline academic journal; another is that the title he gave to the book - Strategic Employment Policy (1991) - is not likely to attract HRM researchers and does not well indicate that the book is about micro (firm) level ES's. Part of the contribution of this paper, therefore, is to call HRM researchers' attention to Begin' neglected ES model.

Begin observes that organizational scholars have sought to identify distinct patterns of organizational design. These designs can be thought of as organizational architectures or configurations. The starting-off point for his book are three connected propositions: (1) an ES that is, the system that structures and coordinates the inflow, utilization, and outflow of the labor input -- is a necessary component of every organizational design; (2) firms choose the ES that best fits their organizational architecture so both are well aligned with each other and with effective accomplishment of the organization's objectives; and (3) diverse internal and external contingencies across firms lead them to design distinctly different organizational architectures which lead, in turn, to the design of distinctly different employment systems. The remainder of the book is devoted to elaborating and developing these three propositions. 
Mintzberg concludes that organizational designs sort into six models (ideal types). Begin subsequently drops one of these (the "missionary") and only marginally considers another (the "divisionalized") since both are largely derivative of the other four when it comes to deriving distinct ES's. These four organizational models are: (Begin, 1991, Table 2-2)

* Simple structure: simple/low-cost production technology, dynamic/competitive environment, smaller size, direct and often personal control/coordination from the top. Examples: restaurant, small construction firm, start-up producers, auto dealer.

* Machine bureaucracy: a larger-scale but relatively routinized and sub-divided production technology, a moderate-to significant stable/planned environment, emphasis on narrow skills and task proficiency, tight top-down coordination through formal rules and supervision. Examples: traditional auto assembly plant, public secondary school, railroad, government agency.

* Professional bureaucracy: a more loosely structured/regulated but larger-scale production technology utilizing complex/intangible skills and knowledge; typically a more stable/predictable environment; greater decentralized and discretionary coordination/control; formal rules complemented by professional/social norms. Examples: large law firm, commercial/industrial construction firm, hospital, private university.

Adhocracy: a complex, knowledge intensive, and human-centered production technology, a rapidly changing environment fueled by innovation and learning, competitive advantage based on quality, speed and service, and flatter, looser and decentralized coordination and control. Examples: consulting firm, high-tech engineering/manufacture, pharmaceutical firm. An advanced "high involvement" work system fits here. 
The fifth organizational type Begin considers (noted above) is called the "divisionalized" form. The reason it does not get much additional attention is because the organization is essentially a composite of the four types described above. That is, a classic divisionalized organization is divided into separate operating companies or units that serve different markets or industries. Examples are conglomerate firms (e.g., one firm with divisions in hotels, insurance, and fire equipment) and vertically integrated firms (e.g., steel firms with iron ore mining, water transport, smelting and fabrication operations). Since the divisionalized firm is largely a composite of the other four underlying organizational forms, this means the ES for a divisionalized organization is also a composite and thus lacks independent contribution to the ES typology.

The divisionalized form does usefully call attention to the fact that the organizational structures listed above are ideal types and in reality may co-exist across units of one firm or within in different departments of a given unit. In this regard, these ideal types are developed around what Begin considers is the distinctive core of the organization, with explicit recognition that some non-core parts of the organization may fall outside the ideal type. To further muddy the empirical waters, the ES observed at a point in time in any given unit (or firm) may be "out of equilibrium" in the sense that it is the process of shifting from one form to another in response to changing internal and external contingencies.

Begin's next step is to match an appropriate ES to each organizational type. The result is four distinct HRM configurations: simple ES, machine ES, professional ES, and adhocracy ES.

The critical task for Begin is to identify the attributes of an ES that are most congruent with the external contingencies facing the organization and its internal organizational structure 
and processes, such as form of command and control, nature of the production technology, the structure of jobs, and skill and knowledge requirements for employees. He explores this in considerable depth, with reference to a host of factors. Two examples include (1) the formal vs. informal and vertical vs. horizontal nature of organizational command and control and (2) the narrow vs. broad and simple vs. complex nature of job tasks. Since our study is an empirical test of this model, we omit more detailed discussion of this step in his theorizing and instead move directly to the end product - the predicted HRM characteristics for each of the four ES's.

Table 1 shows the four different ES types across the top and then a group of eight HRM practices (recruiting/staffing, benefits/rewards) and characteristics (work force size, degree of

Table 1. Predicted Characteristics of Begin's Employment Systems

\begin{tabular}{|l|c|c|c|c|}
\hline HRM Characteristic/ES & $\begin{array}{c}\text { Simple } \\
\text { Structure }\end{array}$ & $\begin{array}{c}\text { Machine } \\
\text { Bureaucracy }\end{array}$ & $\begin{array}{c}\text { Professional } \\
\text { Bureaucracy }\end{array}$ & $\begin{array}{c}\text { Adhocracy } \\
\text { System }\end{array}$ \\
\hline Recruiting/Staffing & LI & LF & LI & EF \\
\hline Training/Development & LI & LI & LI & EF \\
\hline Benefits/Rewards & LI & EF & EI & LF \\
\hline Performance Management & N/LI & LF & Many \\
\hline Participation/Voice Mechanisms & Few & Few & Moderate & Varies \\
\hline Work Force Size & Small & Large & Varies & Yes/No \\
\hline Unionization & No & Yes & No & EF \\
\hline Strategic Involvement & N & N/LI & N & Much \\
\hline Degree of Formalization & Little & Much & Little & \\
\hline Definitions: N - none, LI - limited (informal), LF- limited (formal), EI - extensive (informal), EF - extensive (formal) & \\
\hline Source: Table 2-2 and Chapter 5 of Begin (1991) & & & \\
\hline
\end{tabular}


formalization) listed down the left-hand side. It is the bundle of these eight HRM practices and characteristics $(\mathrm{P} \& \mathrm{C})$ that collectively define each ES. Note that the eight $\mathrm{P} \& \mathrm{C}$ include many of the core sub-areas of the personnel/HRM function; also note that Begin's study includes several other HRM practices (e.g., job design) that we omit because our data set does not include them.

As indicated earlier, one reason we chose Begin's ES model is because more than other writers he makes predictions about how these specific, measureable types of HRM P\&C vary across organization types. Unfortunately, these predictions are not made using a common metric but are a mix of quantitative, qualitative and descriptive measures. These different metrics are displayed in the individual cells of Table 1. For example, the level/type of staffing for the four ES's is, respectively LI (little/informal), LF (little/formal), and EF (extensive/formal), while for participation and voice mechanisms the metric is Few, Few, Moderate, Many. These metrics are measuring a mix of rules and activity levels; that is, "little/informal" means that the activity of staffing and the rules governing it are modest sized, not greatly detailed, and offer significant room for discretion. Further, when an activity such as training is marked as "little/informal" this does not mean that the employees are not necessarily highly trained; it does mean, however, that the employees have obtained the training elsewhere (e.g., a medical school) and the organization itself provides only modest and loosely structured training.

Before moving further toward empirical testing, it is useful to examine the nature of the four ES's depicted in Table 1 and offer a brief summary.

The simple ES is exemplified by a restaurant or auto dealer. Begin's model predicts such organizations should fall in the "no/little" and "informal" category for all nine HRM practices. Thus, recruiting/staffing and performance appraisal (development) are little and informal, HRM 
has no integration with organizational strategy, size of labor force is small, and unionization is largely non-existent. These HRM characteristics seem to match with what we know about these kinds of firms.

A machine ES, on the other hand, is exemplified by a traditional auto assembly plant, railroad, or government agency. The machine ES configuration is similar to the simple ES in two cells (training, participation/voice), close in a third (strategy integration) but different in the other five. A machine ES uses limited and informal staffing methods, extensive and formal benefits, limited and formal training/development, few participation/voice mechanisms, employs a large labor force, and is more likely to be unionized. Again, these HRM practices seem in line with expectation.

The professional ES is found in firms such as large law firms, hospitals and private universities. Like a simple ES, the staffing/recruitment function for core employees is modest but also more formalized (e.g., selection of new nurses or professors is formalized but not technically complex), formal in-house training also ranges from little-to-modest (an average of values in Begin's Table 2-2 and 5-6), and most professional ES's are not good candidates for unions - at least among core employees. The professional ES is different, however, by having extensive benefits and greater employee participation/voice devices.

The adhocracy ES is exemplified by consulting firms, high-tech entrepreneurial firms, and firms with "high involvement" production systems. This type of ES is the most "HRM intensive." Because skills, motivation and creativity are important and the technology of production and tight supervision cannot tightly regulate the work process, adhocracies find it necessary to invest substantial resources in carefully selecting, developing, rewarding and 
retaining talent, reflected in extensive/formal staffing, training, appraisal and benefit functions. Adhocracies also provide the most participation/voice mechanisms for core employees, which in turn makes them poor candidates for unions. [Begin, however, gives a Yes score to administrative support employees in an adhocracy, leading us to put a Yes/No entry in this cell.] Because human capital is a major source of competitive advantage, HRM policies/practices are more tightly and explicitly integrated with organizational strategy.

\section{Empirical Analysis}

The object of this paper is to determine if the ES's adopted by actual organizations in the American economy sort into and relatively well match Begin's ES typology. This exercise is a specific test of his model, but it has wider implications since several other studies (described earlier) also develop a four-way typology with ES's sharing many of the same characteristics.

We proceed in four steps. The first is to convert the diverse metrics in Table 1 into a common form that can be used for a cluster analysis; the second is to describe the clustering technique; the third is to describe the data set; and the fourth is to present the results of the cluster analysis.

\section{Metric Conversion}

The first task is to transform all the cell entries in Table 1 into a common metric. We start with the first three HRM practices (recruiting, training, benefits).

These three HRM practices are measured on a scale that shows whether the practice is predicted to be non-existent (N), limited/informal (LI), limited/formal (LF), extensive/informal (EI), or extensive/formal (EF). The measures N, LI and EF correspond in a relatively 
straightforward way to low, moderately low and high usage, respectively. The two remaining categories LF and EI, although less clear-cut, seem reasonably approximated by a ranking of moderate and moderate high.

We next turn these common rankings of low, moderate, high, etc. into numerical scores using a 1-6 scale $(6=$ highest $)$. Each ranking is coded with a score covering a two point range (e.g., 1-2) in recognition that a score such as "low" has some internal variance. Accordingly, $\mathrm{N}$ is given a score of 1-2, LI gets 2-3, LF gets 3-4, EI gets 4-5 and EF gets 5-6.

Next are the other five HRM P\&C in Table 1. Each is again converted into a numerical score using a 1-6 ranking. First, participation and voice mechanisms are ranked in Table 1 as Few, Moderate, or Many. This three-way ranking converts neatly into Few $=1-2$, Moderate $=3$ 4 and Many $=5-6$. Next, the size of the work force, the level of unionization and the degree of formalization variables are ranked using binary measures, such as Small or Large, No or Yes, and Little or Much. These variables are, accordingly, assigned a score of 1-3 for Small, No and Little and 4-6 for Large, Yes and Much. The two cell entries "Varies" (work force size) in Table 1 are coded 1,2,3,4,5,6. Finally, the strategic involvement variable uses the N, LI, LF, EI and EF ranking, as with the three HRM practices discussed above, and is similarly converted to the 1-6 scale.

The results of this metric conversion are depicted in Table 2. 
Table 2. Quantifying the ES Characteristics (1-6 Scale)

\begin{tabular}{|l|c|c|c|c|}
\hline HRM Characteristic/ES & Simple & Machine & Professional & Adhocracy \\
& Structure & Bureaucracy & Bureaucracy & System \\
\hline Recruiting/Staffing & 2,3 & 3,4 & 2,3 & 5,6 \\
\hline Training/Development & 2,3 & 2,3 & 2,3 & 5,6 \\
\hline Benefits/Rewards & 2,3 & 5,6 & 4,5 & 5,6 \\
\hline Performance Management & $1,2,3$ & $3,4,5$ & $3,4,5$ & 5,6 \\
\hline Participation/Voice & 1,2 & 1,2 & 3,4 & 5,6 \\
\hline Work Force Size & $1,2,3$ & $4,5,6$ & $1,2,3,4,5,6$ & $1,2,3,4,5,6$ \\
\hline Unionization & $1,2.3$ & $4,5,6$ & $1,2,3$ & $2,3,4$ \\
\hline Strategic Involvement & 1,2 & $1,2,3$ & 1,2 & 5,6 \\
\hline Degree of Formalization & $1,2,3$ & $4,5,6$ & $1,2,3$ & $4,5,6$ \\
& & & & \\
\hline
\end{tabular}

\section{Data Set}

We use data generously provided by the Bureau of National Affairs (BNA) from its 2005 and 2006 reports, HR Department Benchmarks and Analysis (Joseph, 2005, 2006). These data come from annual surveys of hundreds of American companies in which they are asked a wide range of questions about the structure, organization and strategic involvement of their HR function; the use of and expenditure on a variety of individual HRM practices, and other 
information such as industry, sector, work force size, and unionization. The BNA surveys

provide the most detailed and in-depth information source of firm-level HRM practices known to us.

The 2005 and 2006 surveys include a total of 641 observations. Some observations are entire firms, others are autonomous divisions/subsidiaries within a firm. Only firms with a minimum employment size of twenty-five are included. We removed all duplicates between the two years and all observations with missing information on the eight HRM P\&C in Table 2. The remaining observations are 264 .

A key advantage of the BNA data is that it asks not only about the use of specific HRM practices but also on the dollar expenditure on each practice. A problem in earlier studies is that they only have data on the presence of the HRM practice, but not the expenditure level. Two firms may both report they utilize an HRM practice (e.g., employee participation) yet one is simple and bare-bones (a suggestion box) and another is extensive and state-of-the-art (a plant productivity/quality council). A yes/no presence measure gives an equal value to both the barebones and advanced systems which, evidently, may be quite misleading. An expenditure measure, on the other hand, is likely to much better capture differences in the depth and formalization of the practice.

Clustering Technique

The statistical method used to perform the cluster analysis builds on but improves the technique used by Appelbaum, Bailey, Berg and Kalleberg (2000). They use K-clustering which requires that the number of clusters and their centroids be specified a priori. We instead let the 
data inform these choices by first using a hierarchical agglomerative clustering method and then apply to these results the K-clustering as a second step.

We start with a hierarchical agglomerative clustering technique. Initially, each firm is its own cluster (e.g., the number of clusters $\mathrm{g}=$ the $\mathrm{n}$ observations). The $\mathrm{n}$ clusters are then reduced to $\mathrm{n}-1$ by agglomerating the two least dissimilar clusters and this process continues in an iterative fashion until only one cluster emerges $(g=1)$. The next step is to use these results to choose the number of clusters $(\mathrm{g})$ that best fit the data. We restrict attention to $\mathrm{g} \leq 6$ in order to identify a manageable number of discrete employment systems. Beginning with $g=6$ and moving to $g=1$, we search through each set of clusterings for what is known in the literature as the "sharp step" -- that is, the value of $g$ where combining one more cluster leads to a substantial change in fit but where moving beyond this leads to a small change (see Miller, 2008, for more detail).

The problem with agglomerative clustering is that in early stages of the clustering (a high g) certain observations may be placed in a particular cluster but when the number of clusters shrinks to a lower $g$ these observations may achieve a larger reduction in dissimilarity if they are moved to a new cluster. But the technique prevents this, leading to potential mis-classification. At this point, therefore, we introduce K-clustering. As earlier noted, K-clustering requires that the number of clusters $g$ and their centroids be specified a priori. We use the agglomerative results to specify the initial value of $g$ (at the sharp step) and centroid values. Then the Kclustering partitions the observations across the g groups in a manner that minimizes the squared distance of each observation from its centroid. Once the firms have been so grouped, the centroids for the clusters are recalculated and the firms are re-clustered. If any of the firms move 
from one cluster to another, the centroids are recalculated and the firms are accordingly reclustered. The K-means clustering method is complete when no firms move between clusters.

Results

To put the clustering analysis into better context, we first plot in Figure 1 the distribution of the 264 organizations by their level of (total) HRM expenditure per employee. The data generate a bell-shaped frequency distribution with a distinctly skewed right-hand tail. [A similar distribution, but with less skewness, is obtained when a count of HRM practices is used.] Per capita HRM expenditure ranges from a low of $\$ 152$ to a high of $\$ 8,709$; however, roughly half of employers - those in the middle range between the $25^{\text {th }}$ percentile and the 75 th percentilespend between $\$ 615$ per employee and $\$ 2,069$ per employee for HR activities.

Figure 1. Frequency Distribution, HRM Expenditures per Employee

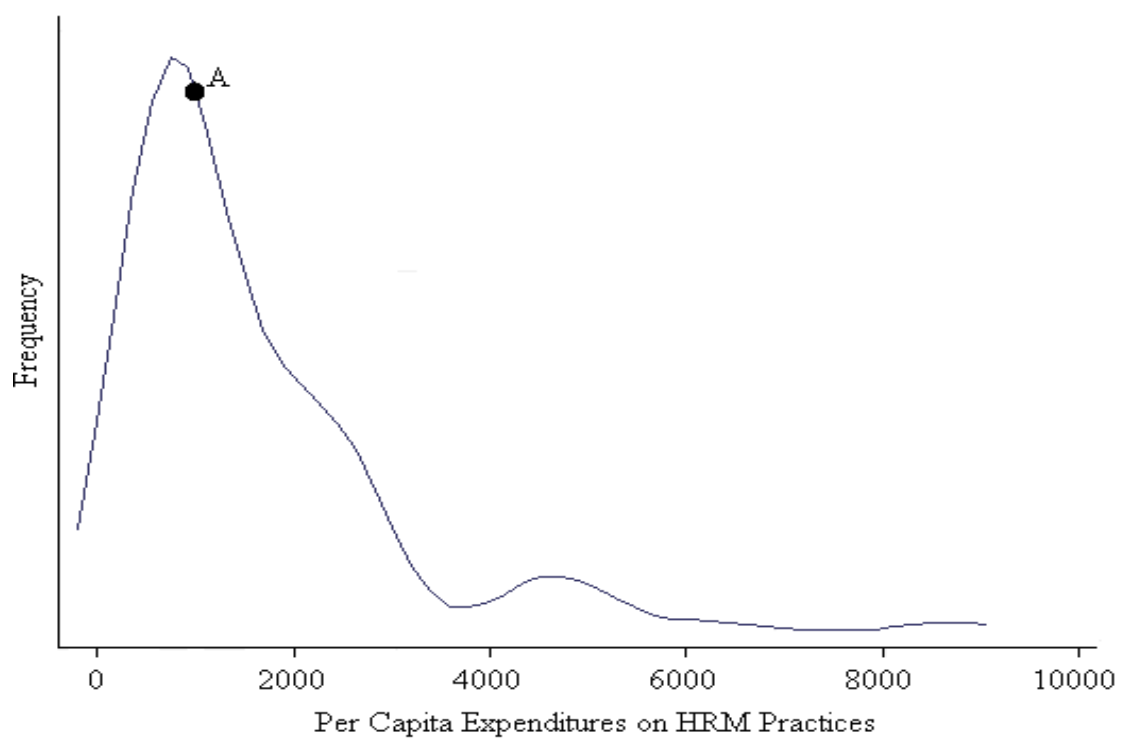

Source: (Joseph 2005; Joseph 2006)

Figure 1 provides two pieces of information supporting the ES and configurational concepts. The first is the huge variance in total HRM expenditures per employee. The 
universalistic SHRM model renders the concept of ES's largely moot since it predicts that only one type of ES (some version of an HPWS) maximizes performance, suggesting long-run competitive selection pressures should concentrate organizations around this model. Since an HPWS is "HRM intensive," the universalistic hypothesis predicts that the HRM frequency distribution should have a relatively narrow variance centered on a high level of HRM expenditure. The data clearly do not support this hypothesis; indeed, the HPWS system appears to be a distinct minority phenomenon located toward the skewed right-hand tail. The lack of empirical support for the universalistic hypothesis may be because the hypothesis is false or, alternatively, because competitive selection pressures are weak, obstructed, or erratic. Whatever the case, the existence of wide range of HRM expenditure levels among the organizations in Figure 1 provides prima facie evidence that firms sort not into one kind of ES but potentially numerous ones.

A second piece of evidence emerges from a more detailed look at one particular point in the HRM frequency distribution. We found in the BNA data a group of three firms with nearly identical levels of HRM expenditure $(\$ 1,010, \$ 1,013$ and $\$ 1,014)$. They are marked as Point A in Figure 1. A weaker version of the universalistic model is that ES's may vary over the entire HRM frequency distribution (due to some contingency factor), but that at a point (or range) firms adopt a relatively homogeneous ES. The data also do not support this hypothesis. We show in Table 3 for each of the three firms the level of their HRM expenditures (ranked Low, Medium, High) allotted to each of nine standard HRM practices (not all in the Begin ES typology). A firm is classified as "Medium" if the percentage of its expenditure on the respective HRM practice is within half a standard deviation of the mean for the dataset; those that are greater (less) are classified as High (Low). 
It is clear that all three firms have selected substantially different HRM bundles. For example, Firms 1 and 2 share in common only three practice levels out of nine (Compensation, External Relations, Strategic Planning); Firms 1 and 3 share four (Training, Benefits, Employee Relations, and OSHA); and Firms 2 and 3 share only two (Recruitment and Performance Management). Again, the data provide prima facie evidence against the universalistic SHRM model and in favor of distinct ES's.

Table 3. HRM Practice Usage for Three Firms with Similar Total Expenditure

\begin{tabular}{|l|c|c|c|}
\hline Type of HRM Practice & $\begin{array}{c}\text { Firm 1 } \\
(\$ 1,010)\end{array}$ & $\begin{array}{c}\text { Firm 2 } \\
(\$ 1,013)\end{array}$ & $\begin{array}{c}\text { Firm 3 } \\
(\$ 1,014)\end{array}$ \\
\hline Recruitment & High & Medium & Medium \\
\hline Training & Medium & High & Medium \\
\hline Compensation & Low & Low & Medium \\
\hline Benefits & High & Medium & High \\
\hline Employee Relations & Medium & High & Medium \\
\hline External Relations & Low & Low & Medium \\
\hline Performance Management & Low & High & High \\
\hline OSHA & Medium & Low & Medium \\
\hline Strategic Planning & Low & Low & Medium \\
\hline
\end{tabular}

Source: Author's calculations using data collected from (Joseph 2005; Joseph 2006).

Figure 1 suggests the organizations in the BNA data set do not sort into only one ES. Conceptually, however, the range of possible ES's extends from a low of 2 to a high of 264. Figure 1 also provides no evidence on the merits of Begin's ES typology. It is to these twin matters we now turn. 
We proceed through a three step process. The first is to apply the clustering techniques described above to the BNA data in order to identify distinct ES's. The key question from the BNA survey we use is: "Please approximate the percentage of your 2006 [or 2005] HR budget allocated to each area below..." Listed below this question are the nine specific HR functional areas or activities listed in Table 3.

We used the budget share answers from this question to perform the clustering analysis. The best fit (location of the sharp step) is obtained with four clusters $(g=4)$. Thus, the 264 organizations -- using the budget share numbers for the nine HRM practice/activity areas -- sort into four distinct groups of HRM practices. Technically speaking, all that the clustering has demonstrated is the existence of four distinct patterns of association in the data; nonetheless, it does not seem to be a too-large a leap to assert that we find demonstrable evidence that these firms sort into four distinct employment systems.

Table 4 shows the nine HRM practices along the vertical left-hand side, the four cluster groups (Group 1, Group 2, etc.) are arrayed along the top (with number of observations for each), and the individual cells show the average budget share numbers (in percents). The cell entries for each group do not sum to 100.0 because we omitted a number of smaller items that often had missing values.

We now want to transition from the results in Table 4 to a test of the Begin model. To do so, we present in Table 5 the eight HRM P\&C that Begin explicitly identifies as part of his ES typology. Note there is some divergence between the nine HRM practices in Table 4 and the eight in Table 5. The reason is that Begin does not include in his ES typology certain of the 
Table 4. Clustering of Organizations by HRM Budget Share (Nine Practices)

\begin{tabular}{|c|c|c|c|c|c|}
\hline HRM Practice/ES & $\begin{array}{l}\text { Group } 1 \\
\text { (78 obs) }\end{array}$ & $\begin{array}{l}\text { Group } 2 \\
\text { (67 obs) }\end{array}$ & $\begin{array}{l}\text { Group } 3 \\
\text { (63 obs) }\end{array}$ & $\begin{array}{l}\text { Group } 4 \\
\text { (56 obs) }\end{array}$ & $\begin{array}{c}\text { Population } \\
\text { Average } \\
\text { (264 obs) }\end{array}$ \\
\hline Employment/Recruiting & 15.08 & 16.68 & 15.02 & 15.44 & 15.55 \\
\hline Training/Development & 7.32 & 10.76 & 11.07 & 9.02 & 9.54 \\
\hline Compensation & 23.08 & 15.62 & 15.74 & 13.55 & 17.00 \\
\hline Benefits & 22.71 & 22.08 & 21.77 & 25.51 & 23.02 \\
\hline Employee Relations & 4.74 & 5.00 & 5.38 & 6.40 & 5.38 \\
\hline External Relations & 1.34 & 1.69 & 2.46 & 1.80 & 1.82 \\
\hline Health and Safety & 3.61 & 3.91 & 3.60 & 4.30 & 3.78 \\
\hline Personnel/HR Records & 3.18 & 3.64 & 4.24 & 3.55 & 3.65 \\
\hline Strategic Planning & 2.92 & 4.47 & 4.10 & 3.41 & 3.97 \\
\hline
\end{tabular}

HRM practices/activities listed in the BNA survey's HR budget share question used for the clustering reported in Table 4, while on the other hand he does include other HRM characteristics (unionization, size, etc.) not in the budget share data but for which data are provided in other parts of the BNA survey and which can therefore be used for Table 5. The first four HRM characteristics in Table 5 are measured in terms of expenditures per employee (e.g., recruiting/staffing expenditure per capita). Employment and percent unionized are numerical values taken directly from the BNA survey; strategic involvement is measured in the survey on a $1-5$ scale $(5=$ highest $)$ and is also directly used in Table 5 . The characteristic in Begin's typology that has the least explicit counterpart in the BNA data set is "degree of formalization" of the 
HRM program. Based on the supposition that more formalization requires more HR headcount and expenditures on programs and services, we used from the survey "total HRM expenditures per employee" as a proxy measure.

To proceed, we must next scale the numerical values in Table 4 so they match the 1-6 scale used earlier (Table 2) to delineate the four ES's in the Begin model. This scaling process is relatively straightforward since the results of the cluster analysis are already characterized using an ordinal measure. The scale is determined in the following manner. First, the mean and standard deviation are calculated for each of the eight characteristics for the entire population of firms. These terms are represented by $\mu_{\mathrm{j}}$ and $\sigma_{\mathrm{j}}$, respectively, with $\mathrm{j}=\{1,2, \ldots, 8\}$. Then, the mean values of these eight variables are determined for each cluster. These values are given by the term $c_{i j}$ where $\mathrm{i}$ represents the cluster, $g_{\mathrm{i}}$ (i.e., $\mathrm{i}=\{1,2, \ldots, g\}$ ), and $\mathrm{j}$ represents the nine characteristics (i.e., $\mathrm{j}=\{1,2, \ldots, 8\}$ ). Finally, each $c_{i j}$ is assigned a score of $1-6$, referred to as $v_{i j}$ so they are comparable to the predictions shown above. This is done by using $\mu_{\mathrm{j}}$ and $\sigma_{\mathrm{j}}$ to determine the value of $c_{i j}$ relative to the rest of the population of firms in the dataset. The criteria used to determine each $v_{i j}$ is as follows:

if...

$$
\begin{array}{lr}
c_{i j}<\mu_{\mathrm{j}}-0.25^{*} \sigma_{\mathrm{j}}, & \text { then } v_{i j}=1 \\
\mu_{\mathrm{j}}-0.25^{*} \sigma_{\mathrm{j}}<c_{i j}<\mu_{\mathrm{j}}-0.1^{*} \sigma_{\mathrm{j}}, & \text { then } v_{i j}=2 \\
\mu_{\mathrm{j}}-0.1^{*} \sigma_{\mathrm{j}}<c_{i j}<\mu_{\mathrm{i}}, & \text { then } v_{i j}=3 \\
\mu_{\mathrm{j}}<c_{i j}<\mu_{\mathrm{i}}+0.1^{*} \sigma_{\mathrm{j}}, & \text { then } v_{i j}=4 \\
\mu_{\mathrm{j}}+0.1^{*} \sigma_{\mathrm{j}}<c_{i j}<\mu_{\mathrm{j}}+0.25^{*} \sigma_{\mathrm{j}}, & \text { then } v_{i j}=5 \\
c_{i j}>\mu_{\mathrm{j}}+0.25^{*} \sigma_{\mathrm{j}}, & \text { then } v_{i j}=6
\end{array}
$$


Therefore a value of $v_{i j}=1$ implies that the per employee expenditures on recruitment practices for a particular group of firms are less than 0.25 standard deviations from the population average. Similarly, a value of $v_{i j}=2$ indicates that the group's average level of per employee expenditures on recruitment practices is between 0.10 and 0.25 standard deviations from the population mean. The reason that a difference of 0.1 and 0.25 standard deviations from the population mean are used as the threshold values for creating this scale is because they create differentiation in the results. [Other values, such as 1.0 and 0.5 standard deviation, were tried but the results change little.]

Table 5 shows the results of the scaling process.

Table. 5. Scaled Values of HRM Practices in BNA Data, by Cluster Group

\begin{tabular}{|l|c|c|c|c|}
\hline HRM Characteristic/ES & Group 1 & Group 2 & Group 3 & Group 4 \\
\hline Recruiting/Staffing & 2 & 6 & 3 & 5 \\
\hline Training/Development & 2 & 3 & 2 & 6 \\
\hline Benefits/Rewards & 3 & 3 & 3 & 5 \\
\hline Personnel Management & 2 & 5 & 3 & 5 \\
\hline Participation/Voice & 3 & 4 & 2 & 5 \\
\hline Work Force Size & 3 & 2 & 6 & 2 \\
\hline Unionization & 4 & 2 & 4 & 4 \\
\hline Strategic Involvement & 1 & 2 & 3 & 5 \\
\hline
\end{tabular}

To help make these rankings more concrete and user-friendly, we converted them into numerical values, as shown in Table 6. Each cell entry shows the average numerical value for the 
indicated HRM P\&C for the organizations in that ES group, as calculated from the BNA data.

These data show in real life terms the patterns of differentiation among the ES groups and individual HRM P\&C, as well as the large diversity that exists across ES groups.

Table 6. Numerical Values of HRM Practices, by Cluster Group

\begin{tabular}{|l|c|c|c|c|c|c|}
\hline HRM Characteristic/ES & Group 1 & Group 2 & Group 3 & Group 4 & $\begin{array}{c}\text { Population } \\
\text { Average }\end{array}$ & $\begin{array}{c}\text { Population } \\
\text { St. Dev. }\end{array}$ \\
\hline Recruiting & 223.55 & 660.53 & 341.03 & 513.88 & 395.43 & 992.54 \\
\hline Training & 119.69 & 288.55 & 138.18 & 530.35 & 293.37 & 942.59 \\
\hline Benefits Administration & 515.96 & 481.72 & 521.39 & 998.71 & 667.29 & 2506.66 \\
\hline Employee Relations & 99.21 & 154.09 & 50.09 & 220.50 & 138.31 & 414.20 \\
\hline Employment & 1209.57 & 881.54 & 3124.59 & 1566.84 & 1666.55 & 5379.92 \\
\hline Unionization & 0.29 & 0.20 & 0.27 & 0.30 & 0.27 & 0.44 \\
\hline Strategic Involvement & 3.24 & 3.52 & 3.61 & 3.92 & 3.71 & 1.08 \\
\hline Degree of Formalization & 1676.05 & 3349.71 & 3851.98 & 6543.09 & 3572.21 & 15193.44 \\
\hline
\end{tabular}

Now we come to the last table and the end product of this empirical analysis. Table 7 shows in parentheses the scaled predictions from Begin's ES typology and above them in bold type the actual level (scaled) reported for the 264 organizations in the data set. The table has 32 cells $(8 \times 4)$.

The predicted values of the HRM P\&C match the actual values in 28 of the 32 cells $-\mathrm{a}$ "success" average of 87.5 percent. Further, two of the "misses" are off by only one scaled value. 
It seems a fair judgment that this represents a high level of conformance between prediction and outcome, suggesting Begin's model has successfully differentiated the contours of alternative employment systems and the associated bundle of HRM practices and characteristics among them. As Begin hypothesized, the Simple ES is the least HRM intensive, the Adhocracy ES is the most HRM intensive, and the Machine Bureaucracy and Professional Bureaucracy ES's

Table 7. Begin's Predictions (parentheses) and HRM Characteristics (bold), by ES

\begin{tabular}{|c|c|c|c|c|}
\hline HRM Characteristic/ES & $\begin{array}{c}\text { Simple } \\
\text { Structure } \\
\text { Group } 1(78)\end{array}$ & $\begin{array}{c}\text { Machine } \\
\text { Bureaucracy } \\
\text { Group } 2 \text { (67) }\end{array}$ & $\begin{array}{l}\text { Professional } \\
\text { Bureaucracy } \\
\text { Group } 3 \text { (63) }\end{array}$ & $\begin{array}{l}\text { Adhocracy } \\
\text { System } \\
\text { Group } 4 \text { (56) }\end{array}$ \\
\hline \multirow{2}{*}{ Recruiting/Staffing } & 2 & 3 & 6 & 5 \\
\hline & $(2,3)$ & $(3,4)$ & $(2,3)$ & $(5,6)$ \\
\hline \multirow{2}{*}{ Training/Development } & 2 & 2 & 3 & 6 \\
\hline & $(2,3)$ & $(2,3)$ & $(2,3)$ & $(5,6)$ \\
\hline \multirow{2}{*}{ Benefits/Rewards } & 3 & 3 & 3 & 5 \\
\hline & $(2,3)$ & $(5,6)$ & $(4,5)$ & $(5,6)$ \\
\hline \multirow{2}{*}{ Employee Relations } & 3 & 2 & 4 & 5 \\
\hline & $(1,2)$ & $(1,2)$ & $(3,4)$ & $(5,6)$ \\
\hline \multirow{2}{*}{ Work Force Size } & 3 & 6 & 2 & 2 \\
\hline & $(1,2,3)$ & $(4,5,6)$ & $(1,2,3,4,5,6)$ & $(1,2,3,4,5,6)$ \\
\hline \multirow{2}{*}{ Unionization } & 4 & 4 & 2 & 4 \\
\hline & $(1,2.3)$ & $(4,5,6)$ & $(1,2,3)$ & $(2,3,4)$ \\
\hline \multirow{2}{*}{ Strategic Involvement } & 1 & 3 & 2 & 5 \\
\hline & $(1,2)$ & $(1,2,3)$ & $(1,2)$ & $(5,6)$ \\
\hline \multirow{2}{*}{ Degree of Formalization } & 2 & 4 & 3 & 4 \\
\hline & $(1,2,3)$ & $(4,5,6)$ & $(1,2,3)$ & $(4,5,6)$ \\
\hline
\end{tabular}


fall in-between. In terms of the HRM frequency distribution depicted in Figure 1, the Simple ES is toward the left-hand tail, the Adhocracy is toward the right-hand tail, and the Machine and Professional ES's occupy the broad middle.

Not only do these results provide support for the Begin ES model, they also provide support for the more general concept of employment systems and the SHRM configurational perspective, as well as lack of support for the SHRM universalistic perspective. The data in Tables 6 and 7 show that HRM practices and characteristics across these 264 organizations exhibit considerable diversity. Scaled values of HRM P\&C in Table 7, for example, range from the lowest possible value of 1 to the highest possible value of 6 . Similarly, Table 6 shows that HRM expenditure per employee (degree of formalization) for Group 4 firms is almost four times larger than for Group 1 firms.

On the negative side, this very large dispersion in HRM expenditures and practice levels indicates, first, no universalistic "one best" ES exists among these organizations since the data sort into four groups, not one, and/or, second, if there is a best practice HRM system then the pressures on firm to adopt it are very weak, thus allowing the persistence of what is in effect a huge dis-equilibrium. On the positive side, our empirical analysis reveals that firms' chosen level of HRM expenditures and practices are not randomly distributed but, rather, sort into a few relatively well-defined bundles or systems. These bundles, in turn, are configured in ways that are amenable to scientific explanation and empirically accord with principles of organizational design. 


\section{Conclusion}

One of the most significant advances in HRM research in the last two decades has been to take a strategic perspective and look at HRM practices in terms of synergistic bundles that align with and support organizational goals. These bundles have become known as employment systems. A variety of theoretical models of employment systems have been advanced and researchers have made exploratory progress in empirically identifying the existence and structure of alternative ES's.

This paper advances this line of HRM research along several fronts. First, we take an indepth look at one model of ES's that is conceptually sophisticated but seldom cited in the literature. The merits of this model, developed by James Begin, are that it builds ES models explicitly on a foundation of alternative organizational architectures, as advanced by Henry Mintzberg, and it yields a detailed set of predictions about HRM practice configurations among the ES's. Second, we test the predictions of the Begin ES model using improved clustering methods and a unique and highly detailed data set on HRM practices among 264 American organizations. Third, our empirical analysis reveals that these organizations sort into four distinct sets of HRM practices and characteristics, thus supporting not only the Begin ES model but also the more general concept of employment systems and the SHRM configurational perspective. Not only are these results and implications important for advancing strategic HRM research, they come from an empirical analysis that we believe to be the most detailed and sophisticated yet presented. 


\section{References}

Appelbaum, E., Thomas Bailey, Peter Berg, and Arne L. Kalleberg (2000). Manufacturing Advantage: Why High-Performance Work Systems Pay Off, Ithaca, Cornell University Press.

Arthur, J. 1992. The link between business strategy and industrial relations systems in American steel minimills, Industrial and Labor Relations Review, 45: 488-506.

Arthur, J. 1994. Effects of human resource systems on manufacturing performance and turnover, Academy of Management Journal, 37: 670-87.

Baron, J., Burton, Diane, and Michael Hannan. 1999. "The road not taken: Origins of employment systems in emerging companies." In G. Carroll and D. Teece, eds., Firms, Markets, and Hierarchies: 428-64. New York: Oxford University Press.

Begin, J. 1991. Strategic Employment Policy: An Organizational Systems Perspective. Englewood Cliffs: Prentice-Hall.

Begin, J. 1997. Dynamic Human Resource Systems: Cross-National Comparisons. New York: De Gruyter.

Black, Lisa, and S. Lynch. 2001. How to compete: The impact of workplace practices and information technology on productivity, Review of Economics and Statistics, 83: 434-45.

Boxall, P., and K. Macky. 2009. Research and theory on high-performance work systems: Progressing the high-involvement stream, Human Resource Management Journal, 19: 2-23.

Commons, John. 1919. Industrial Goodwill. New York: McGraw Hill.

Delery, J. and Doty, D. 1996. Modes of theorizing in strategic human resource management: tests of universalistic, contingency, and configurational performance predictions. Academy of Management Journal, 39: 802-35.

Dunlop, J. 1958. Industrial Relations Systems. New York: Holt.

Edwards, R. 1979. Contested Terrain: The Transformation of the Workplace in the Twentieth Century. New York: Basic Books.

Fombrun, C., Tichy, N., and M. Devanna. 1984. Strategic Human Resource Management. New York: Wiley.

Guthrie, J. 2001. High involvement work practices, turnover, and productivity: Evidence from New Zealand, Academy of Management Journal, 44:180-90. 
Hendry, C. 2003. Applying employment systems theory to the analysis of national models of HRM, International Journal of Human Resource Management, 14: 1430-42.

Horgan, J., and P. Mühlau. 2006. Human resource systems and employee performance in Ireland and the Netherlands: A test of the complementarity hypothesis, International Journal of Human Resource Management, 17: 414-39.

Huselid, M. A. (1995). "The Impact of Human Resource Management Practices on Turnover, Productivity, and Corporate Financial Performance." Academy of Management Journal, 38(3): 635-672.

Joseph, J. (2005). HR Department Benchmarks and Analysis Report. Washington, D.C., Bureau of National Affairs.

Joseph, J. (2006). HR Department Benchmarks and Analysis Report. Washington, D.C., Bureau of National Affairs.

Katz, H., and O. Darbishire. 2000. Converging Divergences: Worldwide Changes in Employment Systems. Ithaca: Cornell University Press.

Kaufman, B. 2001. The theory and practice of strategic HRM and participative management: Antecedents in early industrial relations, Human Resource Management Review, 11: 505-34.

Kaufman, B. 2008. Managing the Human Factor: The Early Years of Human Resource Management in American Industry. Ithaca: Cornell University Press.

Kerr, C. 1954. "The balkanization of labor markets.” In E. Bakke, ed., Labor Mobility and Economic Opportunity, 92-110. Cambridge: MIT Press.

Lepak, D., and Snell, S. 1999. The human resource architecture: toward a theory of human capital allocation and development. Academy of Management Review, 24: 31-48.

MacDuffie, J. 1995. Human resource bundles and manufacturing performance" Organizational logic and flexible production in the world auto industry, Industrial and Labor Relations Review, 48: 197-221.

Mahoney, T., and J. Deckop. 1986. "Evolution of concept and practice in personnel administration/human resource management," Journal of Management, 12: 223-41.

Marsden, D. (1999). A Theory of Employment Systems: Micro Foundations of Societal Diversity. Oxford, Oxford University Press.

Miller, B. 2008. Estimating the Firm's Demand for Human Resource Management Practices. Doctoral dissertation, Georgia State University. 
Mintzberg, H. 1983. Structure in Fives: Designing Effective Organizations. Englewood Cliffs, NJ: Prentice-Hall.

Orlitzky, M, and S. Frenkel. 2005. Alternative "Low-Involvement Work Practices and Business

Performance.” International Journal of Human Resource Management, 16: 1325-48.

Osterman, P. 1987. Choice of Employment Systems in Internal Labor Markets, Industrial Relations, 26: 46-67.

Pinfield, L. and M. Berner. 1994. Employment systems: Toward a coherent conceptualization of internal labor markets. In G. Ferris, et. al., eds., Research in Personnel and Human Resource Management, Vol. 12, pp. 41-78.

Pudelko, M. 2006. A comparison of HRM systems in the USA, Japan and Germany in their socioeconomic context, Human Resource Management Journal, 16: 123-53.

Thompson, P., and B. Hartley. 2007. HRM and the worker: Labor process perspectives. In P. Boxall, J. Purcell, and P. Wright (Eds.), Oxford International Handbook of Human Resource Management: 147-65. Oxford: Oxford University Press.

Walton, R. 1985. From control to commitment in the workplace, Harvard Business Review, 63: 7784.

Wright, P., and McMahan, G. 1992. Theoretical perspectives for strategic human resource management, Journal of Management, 27: 295-320. 